\title{
djb zur Wahl des Europäischen Parlaments 2014
}

Der djb - Regionalgruppe Magdeburg - und der Bund der Richter und Staatsanwälte in SachsenAnhalt haben am 7. Mai 2014 in das Justizzentrum Eike von Repgow in Magdeburg eingeladen. Es war die erste Veranstaltung, die von beiden Verbänden gemeinsam organisiert wurde. Aus Anlass der anstehenden Wahl zum Europäischen Parlament sollten Justiz- und Gleichstellungspolitik auf den Prüfstand gestellt werden.

Nach der Begrüßung der Anwesenden durch den Präsidenten des Amtsgerichts Magdeburg Dr. Uwe Wegehaupt und den Präsidenten des Oberlandesgerichts Naumburg Winfried Schubert wurde ein bunter Strauß an Themen diskutiert. Die Gleichstellungspolitik auf europäischer Ebene als Thema mit Tradition bot mit dem Reizthema „Quote“ Anlass zu Kontroversen. Auch die mittlerweile auf europäischer Ebene emanzipierte Justizpolitik bot mit der Diskussion um den sogenannten Europäischen Staatsanwalt ausreichend Stoff für Auseinandersetzungen. Grundsätzlich wurde thematisiert, ob wir nicht bereits genug Europa haben oder ob mehr Europa, bis hin zu den „Vereinigten Staaten von Europa “, wünschenswert wäre. Es bestand Einigkeit, dass europäische Gesetzgebung zurückhaltend und nur nach eingehender Prüfung lanciert werden sollte.
Sabine Overkämping Vorsitzende der djb-Kommission Öffentliches Recht, Europa und Völkerrecht

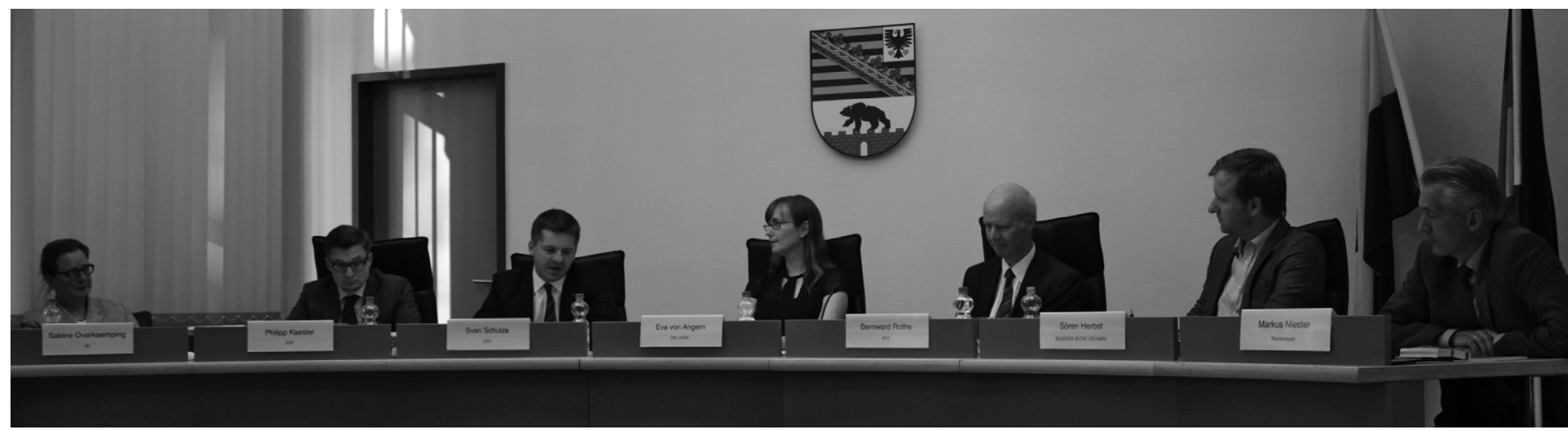

$\Delta$ Für das Podium mit Vertreterinnen und Vertretern der im Europäischen Parlament vertretenen Parteien konnte (v.l.n.r.) für die FDP Rechtsanwalt Philipp Kaesler, der Spitzenkandidat der CDU in Sachsen-Anhalt Sven Schulze, die rechtspolitische Sprecherin der Fraktion DIE LINKE im Landtag von Sachsen-Anhalt und Vorsitzende des Landesfrauenrates Sachsen-Anhalt Eva von Angern, das Mitglied im Landtagsausschuss Recht, Verfassung und Gleichstellung Bernward Rothe, SPD, sowie der europapolitische Sprecher der Fraktion Bündnis 90/Die Grünen im Landtag von Sachsen-Anhalt Sören Herbst gewonnen werden. Sabine Overkämping, Vorsitzende der djb-Kommission Öffentliches Recht, Europa und Völkerrecht (links außen), und Markus Niester, Vorsitzender des Bundes der Richter und Staatsanwälte in Sachsen-Anhalt (rechts außen), haben durch die Veranstaltung geführt (Foto: Carsten Gießler, Richter am Landgericht).

\section{Der djb gratuliert}

\section{Seyran Ateș}

zur Verleihung des Verdienstkreuzes 1. Klasse am 10. Juli 2014 durch Bundespräsident Joachim Gauck. Sie habe sich „in herausragender Weise um die Integration von Zugewanderten und ein gutes Miteinander in unserer Gesellschaft verdient gemacht“, so der Bundespräsident. Ateş musste sich als Kind und Jugendliche zunächst einmal gegen ihre eigene türkischkurdische Familie durchsetzen. Nun engagiert sie sich seit mehr als 30 Jahren auch unter Hinnahme persönlicher Risiken für Frauen und Mädchen aus muslimischen Ländern, denen eigene Rechte nicht gewährt oder die in ihrer Würde verletzt werden.

Seyran Ateş, geboren 1963 in Istanbul, studierte Jura an der Freien Universität, Berlin. Nach Abschluss des Referendariats eröffnete sie ihre erste Anwaltskanzlei und setzt sich insbesondere im Familienrecht für Frauen mit Migrationshintergrund ein. Sie kämpft gegen Zwangsheirat und „Ehrenmorde" und forderte als eine der ersten einen eigenen Straftatbestand Zwangsverheiratung. Ateş nahm sowohl am Integrationsgipfel der Bundesregierung als auch an der Islamkonferenz teil. Wegen gewalttätiger Angriffe und (Mord-)Drohungen politischer Gegner und auch Prozessgegner, gab sie 2006 ihre Anwaltszulassung zurück. Seit 2013 ist sie wieder als Rechtsanwältin in Berlin tätig. Ihr

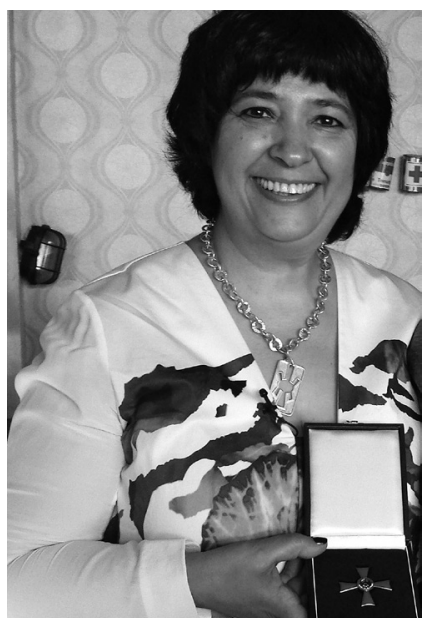

A Seyran Ateș 